\title{
O impossível de ensinar, testemunho de um jeito de corpo: por um mundo menos ordinário, em que a alegria é a prova dos nove
}

\author{
The impossibility of teaching: witnessing body \\ movement; for a less ordinary world in which \\ happiness is the real deal
}

Anna Amélia Faria

Escola Bahiana de Medicina e Saúde Pública (Salvador), Universidade Federal da Bahia (Salvador). Bahia, Brasil. annafaria@bahiana.edu.br

\begin{abstract}
RESUMO | O relato de experiência, neste artigo, sugere o espaço da sala de aula, enquanto grau zero, por onde encontros com conhecimentos se enlaçam aos afetos. Tal junção contribui para um aprendizado mais vivo e acionador de trocas, em que se afirma a ética dos bons encontros, atravessando as usuais, reiteradas e constantes domesticações de corpos e análises comprimidas, estabelecidas nas práticas e histórias canônicas da aprendizagem. A sala de aula pode acionar outras trocas em que entendimentos mais analíticos - e, inclusive, alegres - auxiliam a compreensão dos modos de entender e estar junto, em que outras forças estabelecerão mais sentidos e valores; inclusive, para localizar, em disciplinas/ componentes retratados, que o aprender e entender o campo da psicologia se perfaz no jogo do tempo, da geografia e do prestígio, vistos a partir dessa visada não naturalizadora, em que preponderam pactos invisíveis e legitimadores, situando e firmando maneiras homogeneizantes e prontas para utilizar/ compreender, tanto disciplina quanto o campo da psicologia.
\end{abstract}

PALAVRAS-CHAVE: Ensino. Psicologia. História da psicologia.

\begin{abstract}
The experience report, in this article, suggests the classroom as ground zero, implying that the classroom is where there is an interlaced confluence of knowledge and affect. Such combination contributes towards a livelier learning process, triggering exchanges, where ethics and positive encounters are maintained, spanning the habitual, reiterated and constant domestication of bodies and pent-up analysis, established in the practices and canonical background of the learning process. The classroom can engage in other exchanges where more analytical understandings - and, moreover, happy - assist in the comprehension of means of understanding and of being together, whereby other strengths establish further the senses and values; including, to identify, in the portrayed disciplines/components, that the learning and understanding process in the field of psychology is made up in the play of time, of geography and of prestige, addressed from this non-naturalizing viewpoint, where invisible and legitimated covenants predominate, situating and establishing homogenized means, ready to be used/understood, both as a discipline and in the field of psychology.
\end{abstract}

KEYWORDS: Teaching. Psychology. History of psychology. 


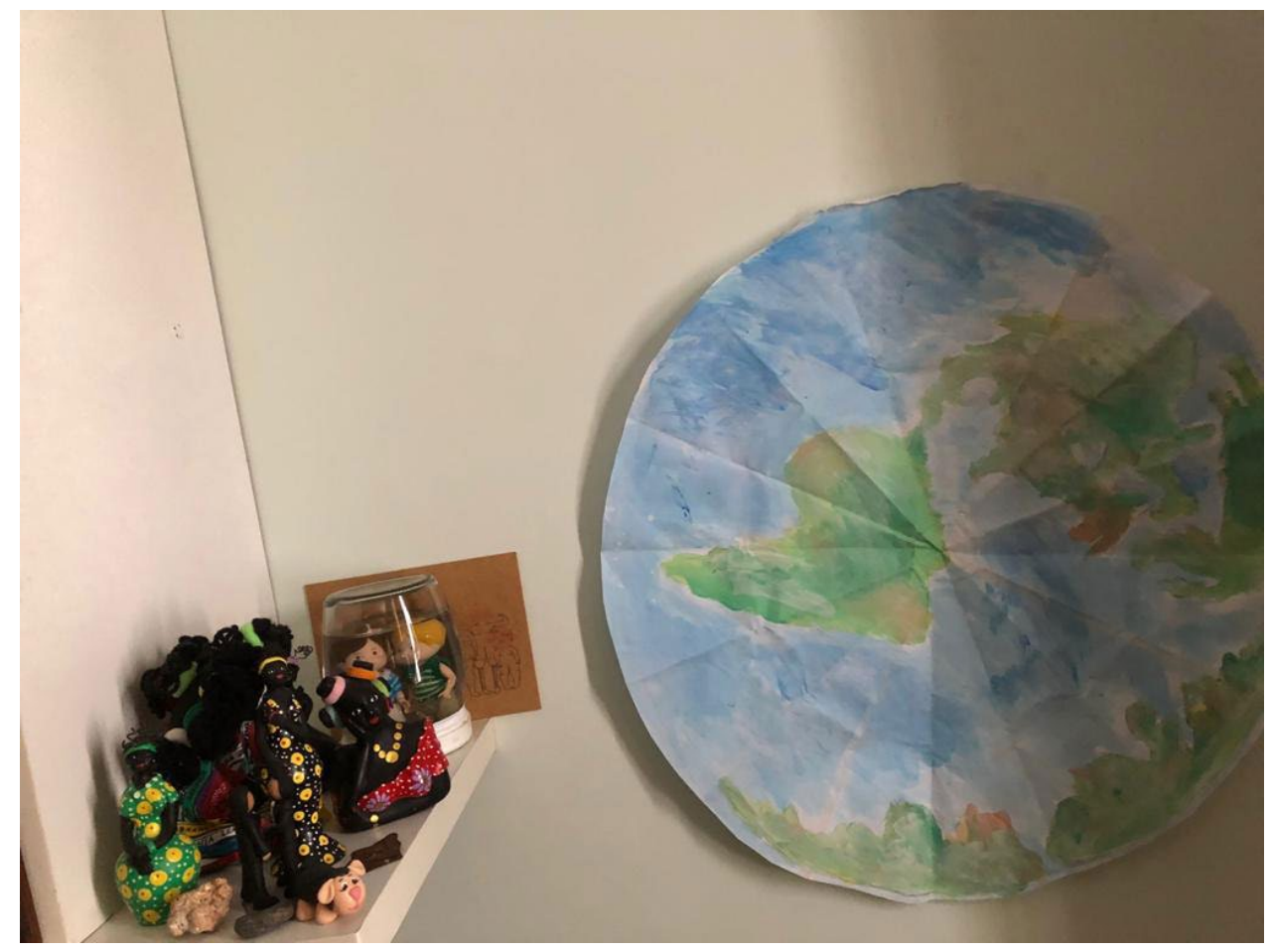

Um começo: fui à Bahiana oito anos atrás, solicitei uma entrevista à coordenadora de então, Mônica Daltro. Estavam, nesse dia, Mônica e Lígia Vilas Boas. Fiquei confiante com a conversa, franca, divertida e sem os subterfúgios capciosos, que podem ocorrer em entrevistas de emprego. Achei a Bahiana bem organizada e bonita. De início, não havia lugar para mim, mas Mônica disse que, assim que houvesse possibilidade, me chamaria. E, um semestre depois desse primeiro momento, entrei e aqui estou. Antes da contratação, houve um encontro com os discentes de psicologia. Nesse dia, conheci Paulo Gonzaga, um dos meus primeiros orientandos e, hoje, um amigo. Emoção, respeito, e, lógico, muito trabalho atravessam a minha história na instituição.

Palavras que guardam outras. Como ensinar o impossível, o amor pelo saber. Didi-Huberman (2011) escreve sobre intermitências, ao relatar o transitar dos vaga-lumes. Emprestando essa variação, penso no conhecimento caracterizado nessa combinação, nunca exclusivamente luz ou escuro, mas criando circuitos de deslocamentos, mesmo quando tudo parece apagado e imóvel. Creio que seja válida essa trama para considerar o conhecimento e a cultura, elementos constantemente acionados durante as aulas. O espaço do conhecimento, situado no além de perspectivas normativas e médias, foi instaurado principalmente no doutorado, com as apresentações de caminhos propostos pela professora e orientadora, Rachel Esteves Lima.

A formação das pequenas luzes traz a natureza iluminada em conformações diminutas, uma pequena luz perfaz caminhos de estímulos e afetos, se inclinando a múltiplos interesses. A sala de aula pode gerar insights, no tempo desdobrado no depois. Considero, então, haver um tempo estendido, capaz de germinar possibilidades. Trabalho em eixos, do necessário e do mistério. Ofereço e ouço perguntas que deixam aberturas, e a sala de aula torna-se um espaço de experiência e, até mesmo, liberdade, em que ideias e trocas podem ser situadas no ponto de interesses e discussões mais amplas.

Para isso ocorrer, valem todos, com todas as perguntas e sugestões. Daí a aula estar situada no campo das produções das presenças, de acordo com o pensamento de Gumbrecht (2010), ainda que eu não abdique da transmissão e do sentido, inscrito na

${ }^{1}$ Fotografia de algumas peças que ganhei, ao longo do ensino na Bahiana 
história e no jogo de interpretação. Vale a hermenêutica, não como exegese exclusiva e exclusivista, mas vale a potência afetante e erótica que o conhecimento pode promover, aquilo que liga. O conhecimento causa, causa presença. Preponderantemente, é assim que busco estar com pessoas, localizadas na condição transitória de discentes, compreendendo que os acontecimentos/aulas/conhecimentos são muito mais do algo a se transmitir, mas chegam como um imã capaz de, nas intermitências, acender/apagar, e a aula presentifica-se como um acontecimento de tentaculares forças criativas, devido ao fato de estarmos junta/e/o/@/x/s, com nossos corpos e histórias, e modos de refletir. Ensinar, portanto, é um afeto, um grau zero, cuja presença feérica aponta para lonjuras, bem além do programa. Reconheço no ensinar uma esthésis, um sensível que, ao tocar, imanta desejos de conhecer. Não há tetos, mas miríades de rotas.

$\mathrm{Na}$ ética do valem todos, vale, inclusive, afastar o metrônomo impactante e emudecedor do certo/errado. Lembremos de Oswald de Andrade sobre "a contribuição milionária de todos os erros." (1995, p. 42). Há mais possibilidades no fale mais sobre isso e, nas pesquisas e narrativas, em retificar e expandir pontos e caminhos. Ainda em Oswald: "Alegria dos que não sabem e descobrem" (1995. p. 41). Então, descobrir é inventar, inventariar, relembrar e narrar, o que permite advirem ideias e reconhecer limites; estudar é uma expansão. Nessa forma de estar com, me vêm novamente as intermitências, do que acende e apaga, e o reconhecimento de que a transmissão estará engendrada em um plano de ensino, imbricado no tempo das singularidades. Por isso a importância de pontencializar a presença, pois a situação que inibe afasta e impede o fluxo das concatenações e afetos. Mesmo não tendo como garantir a mesma coisa para todos, é um dos objetivos que busco alcançar quando estou com as pessoas que estão na sala comigo, sala, inclusive, virtual.

Iniciei as aulas, trabalhando duas disciplinas de Fundamentos: de Psicologia e de Filosofia e Ética, além de ter passado por alguns anos no Programa Candeal: mais amigos e trocas que permanecem. Fundamentos de Filosofia e Ética estava mais integrada a articulações com os interesses estabelecidos durante o mestrado (em Comunicação), o doutorado (Letras), e a pesquisa de pós-doutorado (Artes). O desafio maior foi de iniciar o trabalho com Fundamentos de Psicologia. Simplesmente, porque aprendi a reconhecer a amplitude da psicologia na Bahiana. Quando cursei psicologia, me ligava mais em psicanálise e filosofia. O que me abriu para a psicologia e me vitalizou foi a icônica escrita e reflexões, estabelecidas por Georges Canguilhem:

Procurar uma resposta à questão "O que é a psicologia? torna-se para nós a obrigação de esquematizar uma história da psicologia, mas, é claro, considerada somente em suas orientações, em relação com a história da filosofia das ciência.. (2012, p. 404).

Esquematizando essa história da psicologia, intrincada a domínios e métodos mais amplos, Canguilhem, na condição de pensador da ciência, desnudou adensamentos epistemológicos, políticos, econômicos, históricos, ativados ao longo de épocas e lugares de prestígio. O seu axial texto, escrito para uma conferência em 1956, organiza os eixos que caminham a passos fundos, intrusivos e articulares, do ponto vista ocidental, e suas ativas e espraiadas franjas. Se Canguilhem perfaz esse arranjo de orientação europeia, e expõe razões e métodos que até hoje influenciam, Luís Cláudio Figueiredo e Pedro de Santi oferecem, no livrinho azul "Psicologia, uma (nova) introdução" (2011), uma contextualização cuja linguagem é mais acessível e muito abrangente, capaz de evidenciar o que fora estimulado por Canguilhem. Além do mais, há, em sua escrita, um lado de cá do Equador, o que propicia discussões e interesses pela psicologia do Brasil, tema de um outro componente, dado, logo em seguida, pela competente Marilda Castelar.

Como mencionei, agi, na docência, como a pessoa que colabora com alguém que quer andar de bicicleta ou, relembrando Espinosa, intento promover bons encontros. Na proposição 11 da terceira parte de seu livro Ética, escreveu, "Se uma coisa aumenta ou diminui, estimula ou refreia a potência de agir de nosso corpo, a ideia dessa coisa aumenta ou diminui, estimula ou refreia a potência de pensar de nossa mente." (Espinosa. 2007 p. 177). Sei que levo textos difíceis, mas brinco a sério quando respondo: "e o que é fácil?". Porém, nunca agi na "crocodilagem", exigindo algo que humilhasse, ou tornasse insuportável a aproximação com o texto, por si mesmo, desafiador; 
ao contrário, procurei realizar convites/provocações, colaborando com a perda do medo dos assustadores textos difíceis, na aposta das conexões possíveis nos diferentes pontos de concatenação de cada um.

Na docência, há possibilidades de apresentar assuntos e textos, e, de acordo com o componente ministrado, oferecer uma leitura mais ou menos exegética, ou de interpretação quase unívoca e acabada, ou com leituras/convites para amplitudes, que permitem haver, em relação ao objeto do conhecimento, um nível mais assertivo de rigor. Na docência, o "e", mais que o "ou", cabe melhor nas intenções do aprender. De qualquer sorte, alguns textos nunca estarão circunscritos em compreensões totalizadas. Sendo assim, é estimulante a aproximação desses poliedros, porque habilitam a intuição de infinitas releituras e compreensões. Eles sempre saltam, conforme

Nietzsche (2000) aponta. Ao falar dos pré-socráticos, diz de saltos e do saber/sabor (2000). Pretendo combinar esse tempo expandido, e trabalhar uma ética ativa nas potencialidades do texto.

Para isso, um outro plano, para se estar com o texto e com o ensino e conhecimentos, se realiza no desejo e encantamento, no impossível de ser dito, mas que se torna um mote de procura e de encontros também felizes que, mesmo que nos angustiem, situam perspectivas transformadoras. Um dos vários reconhecimentos à potência de Canguilhem está no fato dele apontar para o drama implícito nas combinações das escolhas e medidas. Ao se evocar um pad(t)rão, a voz invocadora se expõe, na sua história e parcerias. Assim, o trabalho dos historiadores da ciência aponta para o rigor que deixa um resto e rastro, que nos faz olhar àquele que opera decisões. Suas palavras são precisas ao fechar o escrito:

"...quando se sai da Sorbonne pela rua SaintJacques, pode-se subir ou descer; se vamos subindo, aproximamo-nos do Panthéon, que é o Conservatório de alguns grandes homens, mas se vamos descendo, dirigimo-nos com certeza para a Chefatura da Polícia." (Canguilhem, 2012, p. 418).
Consequentemente, as marcas decisórias demonstram-se nas recusas. Dito de outra maneira, a inclusão de processos e medidas propicia trajetos e tráfegos do mundo daqueles que os criam. E o mundo de Canguilhem, igualmente, está tomado nessa rede. Daí a necessidade de outros dimensionamentos políticos para dar oportunidade aos diálogos com outros referenciais, incluindo marcos civilizatórios dos que foram recusados, falados, medidos, cristalizados pelas doutas visões, tomadas nas razões e interesses de seus próprios tempos.

Durante alguns anos, trabalhei com alguns filmes, dentre eles: "Fausto" (2011), de Sokurov, e "Vênus Negra" (2011), de Abdellatif Kechiche. Depois de cada filme assistido, pedia a cada discente que escrevesse uma carta: "O que você diria à Sara Saartjie (Vênus Negra)"? Isso criava uma atmosfera de proximidade e distância com a história daquela que foi exposta no Museu do Homem, até o ano de 2002. O que dizer àquela que foi apresada na tessitura de uma época, em uma Europa orgulhosa de seus preceitos iluministas? Também pedi aos discentes uma carta a Fausto, um cientista inaugural atormentado em uma Europa assolada pela religião, miséria e doenças. No convite ético à escrita das cartas, uma convocação a uma maioria de discentes, mulheres e não brancas, um abrir ao lugar de fala daquelas que necessitam ser mais que um técnico-perito, para fazer bem um trabalho de exercer a psicologia.

Há disciplinas mais pragmáticas e instrumentais, há as mais críticas, inventivas e analíticas, e há as que mixam elementos. Entendo-me, contribuindo com o ensino na Bahiana, a partir dessa terceira viragem, porque a invenção e criatividade alimentam-se de bases já assentadas, podendo ser revisitadas e, muitas vezes, revistas.

Alguma sina e ar, aquilo que oxigena. Nas geografias e culturas, engendradas em tempos e narrações, algumas histórias. As disciplinas de Fundamentos, de psicologia e filosofia, eram em semestre sequenciais, então, pude ter a oportunidade de expandir um entendimento de assuntos que se enlaçavam. Para o componente de Fundamentos de Psicologia,

${ }^{2}$ Enquanto escrevo este artigo, vejo um beija-flor. Nessa quarentena, andei fazendo amizade com que está podendo ir e vir mais que eu. 
utilizei textos que promoviam uma história: da psicologia, da filosofia, das ciências. Menos descrição sobre processo e linhas de trabalho, e mais um olhar sobre o modo como se constituíram. Aprendi a considerar o componente como uma espécie de Aleph: ao rodar na mão o objeto de determinado conhecimento, podemos ver inúmeras outras paisagens na forma multifacetada.

\section{Um conhecimento que se faz método}

Depois da minha pesquisa de pós-doutoramento em artes pela Unb, pude conectar a ideia de a/r/tografia (2013) à produção de objetos. Há anos trabalho com objetos: ebós epistemológicos, flor no asfalto, objetos de si, objetos epistemológicos, etc. Peço para os alunos apresentarem algo que venha como um signo aristotélico, que apresentem, em substância e forma, o assunto a ser encarnado, algo que atravesse a realidade de forma palpável, em uma trama de existência de logos e sentido. Já vi fitas dos Bonfim, carteiras da faculdade, uma lâmina, espelho, chinelo, camisa do Vitória, caderno, elástico de prender cabelo, um grande rolo de papel que contava uma história de separação, a chapa de um órgão, o próprio corpo do estudante que falou: "profa, o objeto é eu.", esmalte, sutiã: a impossível síntese dessa experiência é constatar que tod@s sabem. Mas é preciso escutar essa música de existências que, inclusive, desistem. Muitas vezes, sou avisada quando alguém vai deixar o curso, e também busco ouvir os motivos das muitas escolhas.

A escuta do outro, encarnada pelos discentes, exige uma ética que nunca é completamente satisfatória, mas indica a necessária abertura, para seus tempos, de que algo fisgou na vida de cada pessoa, uma interrogação que caminhará com a existência, e colaborará para uma emancipação e generosidade. Esse é o ensino em que distingo intelectuação e alguma sabedoria.

A sabedoria salta a capacidade compreensiva, percorre um outro senso, pois promove olhar com mais amplitude, ainda que seja um objeto cotidiano. Uma metáfora: usualmente, comento sobre a teoria dos conjuntos, do que contém e do que está contido, digo que o nosso circuito de inteligibilidade e afetos contém, dá forma e densidade aos nossos desejos, mas o universo do outro não ficará nunca submetido ao nosso.
Assim, quem trabalha com psicologia deve ter pés de lã ao se aproximar das singularidades, subjetividades, e de quem sofre, porque, se de um lado o sofrimento apequena, do outro, em cada vivo, habita um infinito que não estará contido no circuito dos valores do profissional de psicologia que dele se aproxima. No quesito infinito, uma das graças de ensinar é a de assinalar a potência heurística do campo. Havendo a história dos conhecimentos aplicáveis de forma mais ou menos pragmática, ela sempre estará marcada por projeções e interesses. Nesse arranjo, está posta a possibilidade inventiva para quem deseja ingressar e contribuir com o campo. Junto a isso, um outro fator mais expansivo é o de virar as costas a condicionamentos ontológicos. O que é do humano eu realmente não sei, e nem voto minha prática de ensino a tal seara, mas o que me fascina são as rotas de desejo. É, mais ou menos isso, que aprendi lendo Stuart Hall (2013): não é de onde viemos, que exclusivamente nos define, mas para onde podemos querer ir, enquanto demiurgos de rotas.

\section{Conflitos de interesses}

Nenhum conflito financeiro, legal ou político envolvendo terceiros (governo, empresas e fundações privadas, etc.) foi declarado para nenhum aspecto do trabalho submetido (incluindo, mas não se limitando a subvenções e financiamentos, participação em conselho consultivo, desenho de estudo, preparação de manuscrito, análise estatística, etc.).

\section{Referência}

Andrade, O. (1995) Manifesto da poesia Pau-Brasil. In O. Andrade. A utopia antropofágica (2a ed.) Globo.

Canguilhem, G. (2012) O que é a psicologia. In G. Canguilhem. Estudos de história e de filosofia das ciências: concernentes aos vivos e à vida. Forense.

Coleção Os pensadores (2000). Preleções sobre a história da filosofia (Nietzsche, F. (1873). In Os pré-socráticos (Torres Filho R. R. Trad.). Nova Cultural.

Dias, B., \& Irwin, R. L. (2013). Pesquisa educacional baseada em arte: a/r/tografia. Editora da UFSM.

Didi-Huberman, G. (2011). Sobrevivência dos vaga-Iumes. Editora UFMG. 
Figueiredo, L. C. M., \& Santi, P. L. R. (2011). Psicologia uma nova introdução: uma visão histórica da psicologia como ciência (3a ed.). EDUC.

Gumbrecht, H. U. (2010). Produção da presença: o que o sentido não consegue transmitir. Contraponto. Puc-Rio.
Hall. S. (2013). Da Diáspora: Identidades e Mediações Culturais (2a ed.) Editora UFMG.

Spinoza, B. (2007). Ética (2a ed.). Autêntica.

\section{Filmes citados:}

Kechiche, Abdellatif. (dir.). Gillibert, Charles et alli (prod.). (2011). Sokurov, Aleksandr. (dir.). Sigle, Andrei (prod.). Fausto. (2011). 